\title{
Theoretical Model on Impact of New Media Communication to Female Consumers Behavior
}

\author{
—Taking Female APP Communication as Example
}

\author{
Daowen Ren \\ School of Management \\ Guangdong Polytechnic Normal University \\ Guangzhou, 510665, China
}

\author{
Xuejun Liu \\ Marketing Department \\ Globaltimes International Consulting Corporation \\ Ontario, L3R0B3, Canada
}

\begin{abstract}
New media is bringing great influence to business mode and social structure. The mobile APP that is a kind of new media brings not only convenience to female lives, but also huge economic benefits to many industries. Based on the the ories of communication and consumers behavior, using the methods of depth interview and literature research, this paper analyzes the mechanism that female APP communication affects the female consumer behavior; and puts forward hypothesis and constructs a theoretical model by following the analytic logic: consumers perception to female APP communication-female consumers intention-female consumers behavior. It takes the lead to do the research in the unified theoretical model. Systematic researches of interaction effects of these variables are also preceded under the situation of new media. The theoretical model provides a new tool of scientific and explanatory power to illustrate the influence on new me dia communication to female consumers' behavior.
\end{abstract}

Keywords-new media; female APP communication; consumers perception; consumers behavior

\section{INTRODUCTION}

Since the 90s of twentieth Century, new media such as cloud computing, mobile Internet and smart phone terminal applications (APP) technology provides information services colorfully, which also changes the traditional mode of economic, lifestyle and social public information. Thus new media brings great influence to the social relationship in business mode and social structure (Gao. 2011). In the field of business and marketing, companies and organizations begin to pay attention to dissemination of information, promotion of brand and product through new media in order to achieve positive effects of marketing. We think the new media communication is based on the microblog, blog, forum, APP, social networks and etc. This paper will focus on the mobile phone APP based new media tools.

The internet tycoon Qihoo 360 released a report called "the green book of trend in China's mobile phone application industry" in March 2015. Data show that China's APP maintained a sustained and rapid growth in the amount of release within a year. Comparing to the previous year, the number of release of APP had a growth of 3 percentage in tools, video, social networking, games or entertainment, etc. The crazy growth of various types of mobile phone APP led to many researchers to do research on development and strategy of App, such as product strategy and requirements, UI design, implementation and test of front-end operations, APP and market, users' relationship etc. According to the characteristics of mobile internet, mobile applications will be an important factor affecting development of mobile internet services. In early 2016, a report from a well-known Internet Co. in Japan show that the time and frequency of usage of female users on APP are much higher than that of usage of male users on APP. Baidu data also show that, compared with the beginning of 2013, the mobile terminal had the highest growth rate of female users, where mobile consumption growth rate reached a maximum of 3 times. Thus, compared to male, female is active users and consumers of smart phone APP and their dependence on APP is far higher than male users.

So, whether it is mobile APP, or female consumers' issue, both are the hot topics of present and future. It is valuable to combine them and study from perspective of communication.

\section{DEPTH INTERVIEWING}

In this paper, the composition of theoretical model is divided into two ways. The first way is depth interview, which is used for qualitative research, and provides a qualitative foundation for the subsequent theoretical model construction. The second way is literature research, which is a kind of qualitative study on the basis of literature and theoretical deduction. Through analysis of the relevant literature, applying the theories of communication, consumers' behavior and female consumers' psychology, this paper brings forward some hypothesis and constructs the theoretical model of impact of female APP communication to female consumers' behavior.

At the beginning of 2017, the authors interviewed 2 women App designers and 5 women App users. Two designers were interviewed by the way of one-on-one in-depth interviews, and at least, two designers have involved in the design of one App, who have deep understood about the App designing principle and designing process and users habits. Content of the interview revolves around essential characteristics, functions and users stickiness to female APP. The following key points will be strongly considered by integrating two designers' answers: (1) perceived vividness of female APP communication: information spread by female App is show as much as possible with text, colors, symbols, as well as background music, animation, pictures and other elements. Vivid information can motivate female consumers desire.(2) 
perceived easiness of female APP: female users who first contact with female App can easily study and grasp the operation way. (3) Users habits: to reduce operation differences of female App and mainstream App, modes of mainstream App operation are applied during the design of female App.

Interviewing to 5 female APP users was used in the form of group interviewing. The group has graduate and undergraduate students, teachers, employees and civil servants, who all have applied experiences about female App. Their consumption patterns, consumption level, income level are also different. The topics of interviews mainly focused on impact of female App communication on their consumers' behavior. The answers can be concluded as follows (see TABLE I):

TABLE I. INTERVIEW SUMMARIES

\begin{tabular}{|c|c|c|}
\hline & $\begin{array}{c}\text { Impact factors } \\
\text { (Perception) }\end{array}$ & Reason explanation \\
\hline 1 & $\begin{array}{l}\text { Vividness of female } \\
\text { app communication }\end{array}$ & $\begin{array}{l}\text { Information spread by female App is show as } \\
\text { much as possible with text, colors, symbols, } \\
\text { background music, animation, pictures and } \\
\text { other elements. Vivid information can motivate } \\
\text { female consumers' desire. }\end{array}$ \\
\hline 2 & $\begin{array}{l}\text { Participation of } \\
\text { female app } \\
\text { communication }\end{array}$ & $\begin{array}{l}\text { Female users can evaluate and comment to their } \\
\text { purchased goods by female app } \\
\text { communicating. Comment \& spreads are } \\
\text { expressed by female consumers. }\end{array}$ \\
\hline 3 & $\begin{array}{l}\text { Interactivity of } \\
\text { female app } \\
\text { communication }\end{array}$ & $\begin{array}{l}\text { Users can interact with other consumers by } \\
\text { female app communication to explore the } \\
\text { services, goods and other related information. }\end{array}$ \\
\hline 4 & $\begin{array}{l}\text { Follow of female } \\
\text { app communication }\end{array}$ & $\begin{array}{l}\text { Majority female consumers have follow } \\
\text { behavior, which urges female consumers to } \\
\text { change their consumption behavior intention } \\
\text { during female app communicating. }\end{array}$ \\
\hline 5 & $\begin{array}{l}\text { Usefulness of } \\
\text { female app } \\
\text { communication }\end{array}$ & $\begin{array}{l}\text { Sharing and evaluation of commodity } \\
\text { information by other members as female app } \\
\text { communicating provide useful information for } \\
\text { consumers’ purchase decision. }\end{array}$ \\
\hline 6 & $\begin{array}{l}\text { Simplicity of } \\
\text { female app } \\
\text { communication }\end{array}$ & $\begin{array}{l}\text { It is simple and easy to buy some commodity } \\
\text { on female APP, at any time and any place. }\end{array}$ \\
\hline 7 & $\begin{array}{l}\text { Discount of female } \\
\text { app communication }\end{array}$ & $\begin{array}{l}\text { It's easier to get discount through female apps } \\
\text { communication, and the size and extent of the } \\
\text { discount is often bigger and deeper. }\end{array}$ \\
\hline
\end{tabular}

According to the above key viewpoints, the paper gets some factors of female APP communication impacting female consumers behavior is: perceived vividness, participation, interactivity, simplicity, usefulness, follow and discount. Because the depth interviews are limited about the samples, it causes the one-sided results of qualitative analysis. So the authors continue to research on content of literature and theoretical deduction to get relatively general, clear and accurate viewpoints, and construct the theoretical model.

\section{THEORETICAL HYPOTHESIS}

\section{A. Relationship between female perception to female App communication and female consumers intention}

1) Perceived vividness of female App communication. Design of female App pay more attention to text, color and symbol than that of general APP (Leanne Li, 2015). Female APP use text, colors, symbols, background music, animation, pictures and other elements to raise female APP vividness and improve female APP aesthetic features. The vivid and aesthetic features form a strong influence to the female senses, so that motivates the female consumption desire. At the same time, these provide a joyful environment on the product information. The positive external environment also will have a positive influence on female consumers' desire. Steuer (2010) got the research result: vividness is the way that the media environment presents information to the sense organ, who divided the vividness into depth and breadth. Depth means the extent to which the media can motivate the senses organ. Breadth means the number of senses of hearing, vision, touch and so on that the media can motivate. For example, the more beautiful and vividness the picture are, the stronger the abilities to awaken the senses are, the higher the depth is. The experimental results of Sewak et al. Pointed out that, in the case of the same information content, high vividness brings stronger visual allure and more joyful, which makes consumers have more positive attitude to consume. According to the above analysis, this paper puts forward the hypothesis:

H1: Perceived vividness of female App communication has a positive influence on female consumers' willingness.

2) Perceived interactivity of female App communication. Female consumers perceive the social function and interaction while female App offers the perfect transmission mechanism for female consumers. Compared to the male, the female emotions are more sensitive and delicate; female language ability usually has an advantage. Female are naturally good at expression, who would like to talk with others and share their experience. The interactivity of female App communication meets the desire of female communication, expression and sharing, displays their emotional needs. At the consumption scenarios during female App communication, sharing information is a mutual transmission mode. Information is shared not only by person but also social groups and community. This interaction and transmission at any time may affect female consumers' desire. Taiwan magazine Belle created a magazine reading App for female fashion desire. The consumers can easily check the model's clothes and accessories by the design of interactive functions. Making up can also be "e-tried", and the consumers can see the test results. Also sensitivity of fashion may be tested interactively. Sicilia (2005) thought that the consumers can have higher flow experience in the interactive website, resulting in a more positive attitude to products. Lombard et al (2001) also got the result: interactivity gives the consumers higher immersion so that the consumers have a more positive attitude to products. According to the above analysis, this paper puts forward the hypothesis:

H2: Perceived interactivity of female APP communication has a positive influence on female consumers' intention.

3) Perceived simplicity of female App communication. Simplicity is simple and easy to use, which is the process of simplifying presentation of information. Provided main information need ensure to understand, remember and operate easily. Most of users interface design of female APP meets the 
need of "waiting time in two seconds", and "less than three steps to use". The mobile terminal offers easiness to let the female take advantage of fragmentation time to select and buy goods quickly (Lei, 2016). For example, if the women want to buy a dress, they open the mobile to seek on the APP. All kinds of dress will be shown at the present. If they want to know the quantity of goods and merchant service, they may find many other customers' remark and feedback when seeking the goods. Because female App is simple and easy to use, it saves a lot of time and cost, makes women very strong consumption willingness. Venkatesh and Morris (2004) in the research of mobile transaction found that: female perceived simplicity of operation is more important than male perceived ease of operation. Based on the above analysis, we put forward the hypothesis:

H3: Perceived of simplicity of female APP communication has a positive impact on female consumers intention.

4) Perceived participation of female APP communication. Female APP has sporadic characteristic and personalization, fragmentation and so on, which reflects the female consumers can participate the process of production content, communication and change during APP transmission. Difference of consumers' participation to female APP communication directly influences the passion of consumers to browse commodity information, buy and evaluate goods. Schindler and Bickart (2006) thought that the forum can make consumers pay more attention to the goods to form a shopping desire than company website by comparing forum and company website. Because of participation of a forum is more extensive, information communication don't have limit of space and time, can also well protect consumers' privacy. The consumers can get commodity evaluation and other consumers information at any moment, which strengthens consumers' perception of commodity virtually. The female with different labels will assemble in different network communities with same consumption and characteristics intention. They are classified in a tribal group according to the different needs of development of APP with socialized characteristics. For instance, Qu Fang, the co-founder of "little red book" introduces that "little red book" has now been the largest overseas shopping sharing community, with 1.5 million consumers, $90 \%$ are female. According to the above analysis, the hypothesis puts forward the hypothesis:

H4: Perceived participation of female APP communication has a positive influence on female consumers' intention.

5) Perceived usefulness of female APP communication. Perception of usefulness of female APP communication refers to female consumers perceives use value as female App transmission. According to the technology acceptance model (Davis, 1989), the degree that female customers perceive usefulness about female APP transmission has a direct impact on female consumers intention. The more useful female consumers perceive female App communication, the more they use female App. As results, they recognize much more the released value of goods by App communication. Gefen (2003) believed that internet is a bridge between the consumers and the enterprises. During transmission process, internet will pass actively product itself into the hands of the enterprise, and important communication of information is whether the product itself is useful or not. Chen \& Tan (2004) found: online shopping, consumers perceived usefulness will have a positive impact on consumers' attitudes. The research of Vijayasarathy (2004) showed that: perceived usefulness by consumer can be used to predict consumers attitude of the online store, namely, there is a significant positive correlation between the two. Hence this paper assumes that:

H5: Perceived usefulness of female APP transmission has a positive influence on female consumers' intention.

6) Perceived discount of female App communication. Many firms give the lower prices for the same commodity, and introduce preferential motivations and rewards, such as electronic coupons or exclusive prizes and so on to allure female consumers' interests. Nielsen in 2012 issued a report on mobile App consumption, and pointed out that the usage of App coupon makes consumers to have more loyalty, which the APP users spend 66\% monthly more than those who do not use APP. Survey of HPI found that consumers are willing to accept mobile marketing from which they can get rewards including electronic coupons. 88\% of respondents said they can accept the mobile marketing, 30\% of respondents like the mobile marketing. Many firms are willing to provide consumers with electronic coupons. Raskino. M. (2001) concluded advantages about electronic coupons: (1) it is easy to select target population by consumers' mobile phone number; (2) consumers can immediately enjoy business discount; (3) consumers can make efficient trading operations by the bar code. In a word, we make the following assumptions:

H6: Perceived discount of female App communication has a positive influence to female consumers' intention.

7) Perceived follow of female App communication. Richard \& David (2008) thought when a person perceived others around him supporting or affirming him to act a behavior, the intention to act the behavior will become very strong. Humans have the sociability, and they will be affected by other people and organizations. Their behaviors are influenced by others opinions, evaluation and behavior. Compared with the male, the female have a deeper follow mentality. Follow will subtly encourage female to make a choice whether they pursuit the popular trend, or change their behavior intentions. During the process of consumption, female will listen to other people's evaluation of the commodity, and will care about sale of commodity. Products with higher evaluation tend to allure more choices by female. On one hand, female gain the consumer information through new media and interpersonal communication, accept all sorts of different habits and consumption concepts. On the other hand, they are happy to communicate information, and hoping 
to impact others consumers behavior. The female consumers are easily impacted by their friends' viewpoints. According to the above analysis, this paper puts forward the hypothesis:

H7: Perceived follow of female App communication has a positive influence to female consumers' intention.

\section{B. Relationship between female consumers intention and} female consumer behavior

The research of consumers' behavior in marketing is based on purchase intention since the 90s of last century. Whether consumers' intention can predict the consumers' behavior or not is the main argument in study of relationship between consumers intention and consumers behavior. The theory of reasoning action (TRA) (Martin Fishbein and Icek Ajzen,1975), the theory of planning behavior(TPB) (Ajzen,1991), the technology acceptance model (TAM) (Davis,1989) all verified that the consumers intention have a positive affection to consumers behavior. According to the above analysis, the hypothesis puts forward the hypothesis:

H8: Female consumers' intention plays an intermediate role in the perceived female consumers' behavior.

H9: Female consumer intentions have a positive affection to female consumers' behavior.

\section{THEORETICAL MODEL}

According to the questions of study, this paper has constructed a systematic theoretical model about the impact of female APP communication to their behavior (see Fig. 1.). The relationships are perceptions of female APP communication, female consumers' intention and female consumers' behavior.

On the basis of the case interview and group discussion, this authors integrate the perceptions of female APP communication, female consumers intention and female consumers behavior into a unified theoretical framework. The main variables include perceptions of female APP communication, female consumers' intention and female consumers' behavior. The perceptions of female APP communication are explanatory variables (independent variables), female consumers' intention is the intermediate variable, and female consumers behavior is a variable explained (dependent variable). The perceptions of female APP communication are divided into 7 variables: perceived vividness, perceived simplicity, perceived interactivity, perceived usefulness, perceived participation, perceived preference/discount and perceived follow.

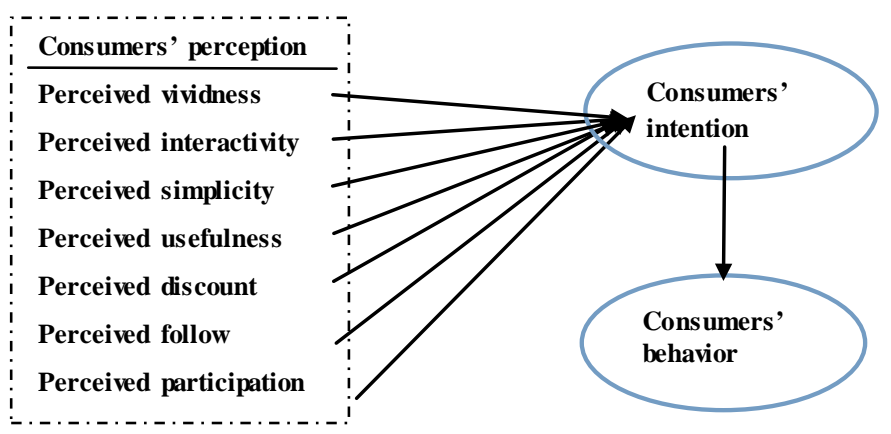

Fig. 1. Theoretical model of impact of female APP communication to female consumers behavior

\section{CONCLUSION}

Combining existing related literature, the authors analyze and bring forward nine relevant research assumptions and a theoretical model that new media communication affects female consumers behavior by following the analytic logic: consumers perception to female APP communicationfemale consumers intention-female consumers behavior. The authors analyze the influences of female consumers' perception on vividness, participation, interactivity, simplicity, discount, usefulness and follow of female APP communication to the consumers' behavior. It takes the lead to do the research in the unified theoretical model. Systematic researches of the interaction effects of these variables are also preceded under the situation of new media. The theoretical model provides a new tool of the scientific and explanatory power to illustrate the influences on new media communication to female consumers' behavior. The paper solves effectively that the previous research only used a specific variables to study the relationship of the specific variables and female consumers' behavior.

\section{ACKNOWLEDGMENT}

This research was financially supported by the project of the normal university characteristic innovation of Guangdong province in 2018 and by the project of the Philosophy and Social Science in Guangzhou in 2018 (2018GXGJ73).

\section{REFERENCES}

[1] Ajzen. The theory of planned behavior [J]. Organizational Behavior and Human Decision Press, 1991, pp.179-211.

[2] Chowdhury, H. K., Parvin, N., Weitenberner, C.,\&Becker, M. Consumer Attitude Toward Mobile Advertising In An Emerging Market: An Empirical Study[J]. International Journal of Mobile Marketing. 2006.1, (2), pp.33-42.

[3] Davis, F. D., Bagozzi, R. P. \& Warshaw, P.R. User Acceptance of Computer Technology: A Comparis on of Two Theoretical Models [J]. Management Science, 1989(35), pp.982-1003.

[4] Gao Gang, Network politics: from the form civilization to digital civilization, network communication,2011(2).pp.36-38 (In Chinese)

[5] Gefen, D., Karahanna, E. \& Straub, D. W. Trust TAM in on-line shopping: an integrated model. MIS Quarterly, 2003,27(1),pp.51-90.

[6] Lombard M, Jennifer S. Interactive advertising and presence: A Framework[J].Journal of Interactivity Advertising.2001,1(2);67-79.

[7] Lei-da Chen\&Justin Tan. Technology Adaptation in E-commerce: Key Determinants of Virtual Stores Acceptance [J]. European Management Journa, 2004.22(1), pp.74-86.

[8] Martin Fishbein \& Icek Ajzen. Belief, Attitude, Intention, and Behavior:a n Introduction to Theory and Research,: Addison-Wesley Publishing Company, 1975.

[9] Richard Cooke\&David P. French. How Well Do the Theory of Reasoned Action and Theory of Planned Behavior Predict Intentions and Attendance at Screening Programs?[J].Psychology \& Health, 2008,23, (7), pp.745-765.

[10] Sicilia M, Kuiz S. et al: Effects of Interactivity in a Web Site: the Moderating Effect of Need for Cognition, Journal of Advertising.2005.34 (3), pp.31-45.

[11] Schindler.R.\&Bickart.B. Published word-of-mouth: Referable, Consumer Generated Information on the Internet[M].Hauvgedt. K. Machleit and R. Yalch. Online Consumer Psychology; Understanding and Influencing Behavior in the Virtual World. New Jersey. Lawrence Erlbaum Associates.2005:pp.35-62. 
[12] Sewak. Saurabh S, Direct Consumer Advertising Via Internet: the Role of Website Design [J], Research in Social \& Administrative Pharmacy: RSAP, 2005, 1(2): 289-309

[13] Siqi Lei. Impact of New media to female consumers' behavior. Communication and copyright. 2016.2 (In Chinese)

[14] Venkatesh, V., Morris, M.G., Davis, G.B. and Davis, F.D. User Acceptance of Information Technology: Toward a Unified View. MIS Quarterly, 2003.27, PP.425-478.
[15] Vijayasarathy Leo R, Predicting Consumer Intentions to Use On-line Shopping: the case for An Augmented, Technology Acceptance Model, Information \&Management, 2004.41(6), pp. 747-762.

[16] Yanan Li, Yinhe Chui Explore the path how news app improves the customers' experience, News world. 2015.7.pp132-133 (In Chinese) 